\title{
Inverted indium-tin-oxide-free cone-shaped polymer solar cells for light trapping
}

\author{
Hongyu Zhen, Kan Li, Zhuoyin Huang, Zheng Tang, Rengmao Wu, \\ Guolong Li, Xu Liu and Fengling Zhang
}

\section{Linköping University Post Print}

N.B.: When citing this work, cite the original article.

Original Publication:

Hongyu Zhen, Kan Li, Zhuoyin Huang, Zheng Tang, Rengmao Wu, Guolong Li, Xu Liu and Fengling Zhang, Inverted indium-tin-oxide-free cone-shaped polymer solar cells for light trapping, 2012, Applied Physics Letters, (100), 21, 213901.

http://dx.doi.org/10.1063/1.4720176

Copyright: American Institute of Physics (AIP) http://www.aip.org/

Postprint available at: Linköping University Electronic Press

http://urn.kb.se/resolve?urn=urn:nbn:se:liu:diva-78816 


\title{
Inverted indium-tin-oxide-free cone-shaped polymer solar cells for light trapping
}

\author{
Hongyu Zhen, ${ }^{1,2, a)}$ Kan Li, ${ }^{1}$ Zhuoyin Huang, ${ }^{1}$ Zheng Tang, ${ }^{2}$ Rengmao Wu, ${ }^{1}$ Guolong Li, ${ }^{1}$ \\ Xu Liu, ${ }^{1}$ and Fengling Zhang ${ }^{2, b)}$ \\ ${ }^{1}$ State Key Laboratory of Modern Optical Instrumentation, Zhejiang University, Hangzhou 310027, China \\ ${ }^{2}$ Department of Physics, Chemistry and Biology (IFM), Linköping University, Linköping SE-581 83, Sweden
}

(Received 19 March 2012; accepted 3 May 2012; published online 21 May 2012)

\begin{abstract}
Based on the flexibility of polymer film, cone-shaped polymer solar cells (PSCs) are fabricated and studied. Effective light trapping is achieved due to multi-absorption in all $360^{\circ}$ directions. Monte Carlo ray tracing is used to simulate the absorption of cone-shaped PSCs with two variables: wavelength and half cone angle. With an inverted indium-tin-oxide-free device structure, a $43 \%$ enhanced light utilization without loss of material utilization is realized in the cone-shaped PSCs with a half cone angle of $45^{\circ}$, compared with the planar PSCs. (C) 2012 American Institute of Physics. [http://dx.doi.org/10.1063/1.4720176]
\end{abstract}

Polymer solar cells (PSCs) based on conjugated polymers and fullerene derivatives attract much attention for the advantages of low cost, large-area, flexibility, and light weight. ${ }^{1-3}$ The low charge carrier mobility of conjugated polymers requires the active layer of the PSCs to be thin enough to facilitate charge transport; as a results, the optical microstructures for light trapping and redistribution ${ }^{4-6}$ are not as effective as those in the silicon solar cells. ${ }^{7}$ Tandem $\mathrm{PSCs}^{8-10}$ can thus harvest more solar photons by using multiple active layers with complementary absorption bands, which may, however, bring a complexity to the device fabrication. Unlike the investigation on the microstructures in the active layer, ${ }^{11}$ study on PSCs with optical macroscopic structures is rarely reported. V-shaped lateral tandem PSCs with absorbing the reflection from adjacent cell were demonstrated by Inganäs. ${ }^{12-14}$ Double light absorption was achieved in the reflective lateral tandem cells comprising two sub cells with complementary absorption spectra. ${ }^{12}$ Multifolded PSCs made on flexible substrates offered a feasible approach in roll-to-roll printing. ${ }^{14}$ At the same time, V-shaped organic solar cells with different active layers and various thicknesses were also reported by Peumans. ${ }^{15}$ $\mathrm{V}$-shape is not monopolized by an organic solar cell; inorganic V-shaped solar cells can also be achieved by splicing the different planar cells. Moreover, $\mathrm{V}$-shaped solar cells are sensitive to the angle of incident light. Here, we present cone-shaped PSCs with a $360^{\circ} \mathrm{V}$-shape structure to enhance the light trapping effect. The cone-shaped PSCs are studied based on both optical simulation and experiment. All functional layers of cone-shaped PSCs are working in a bending state, which is hardly realized in inorganic solar cells. By changing the vertex angles of the cones, it is easy to dilute incident light irradiating on the active layers of solar cells per unit active area, which could potentially improve both the power conversion efficiency (PCE) and lifetime of PSCs. ${ }^{16}$

In this study, indium tin oxide (ITO)-free cone-shaped PSCs were fabricated based on planar PSCs. Conjugated

\footnotetext{
${ }^{\text {a)} E-m a i l: ~ h o n g y u z h e n @ z j u . e d u . c n . ~}$

b)E-mail: fenzh@ifm.liu.se.
}

polymer poly[2-methoxy-5-(2'-ethylhexyloxy)-p-phenylene vinylene] (MEH-PPV) was used as an electron donor for its high stability and good film quality in a large area, and phenyl- $\mathrm{C}_{71}$-butyric acid methyl ester $\left(\mathrm{PC}_{71} \mathrm{BM}\right)$ served as an electron acceptor due to its superior light absorption to $\mathrm{PC}_{61} \mathrm{BM}$. Unlike flexible polymer films, a tensile stress can crack metal electrode. ${ }^{17}$ So the inverted structure: $\mathrm{Al}(80 \mathrm{~nm}) / \mathrm{TiO}_{\mathrm{x}}(2 \mathrm{~nm}) / \mathrm{MEH}-\mathrm{PPV}: \mathrm{PC}_{71} \mathrm{BM}(60 \mathrm{~nm}) / \mathrm{PH} 1000$ $(100 \mathrm{~nm})$ is used, and all the functional layers of the cone PSCs will work in a compressive stress. The choose of nonindium electrode in this study well meets the necessity of commercializing PSCs. ${ }^{18,19}$

Due to the oblique incidence and multi-reflections in the cone-shaped PSCs, device performances strongly depend on vertex angle of the cone and optical characteristics of the functional layers within the device. Systematic evaluation of the optical input in the cone-shaped PSCs with various angles is important for the structural design and device optimization. The optical constants of the functional layers are obtained from transmission measurements, which are performed with a Perkin-Elmer Lambda 950 spectrophotometer at normal incidence. The transmission spectra of the MEH-PPV:PC ${ }_{71} \mathrm{BM}$ and PH1000 films on glass substrate are presented in Fig. 1(a). Based on the characteristic matrix of the film, ${ }^{20}$ the transmission spectra can be fitted by Forouhi-Bloomer dispersion model to extract the optical constants of the film. ${ }^{21}$ The extracted refractive indices $(n)$ and extinction coefficients $(k)$ of these films are shown in Fig. 1(b). The $n$ of MEH$\mathrm{PPV}: \mathrm{PC}_{71} \mathrm{BM}$ are variable in the region of $1.65-1.95$ from 380 to $780 \mathrm{~nm}$, and the $k$ of MEH-PPV:PC ${ }_{71} \mathrm{BM}$ presents high values up to $600 \mathrm{~nm}$. PH1000 served as the transparent anode presents smaller $n$ and $k$ in the visible region.

We use Monte Carlo ray tracing to compute optical flux as it propagates through the cone-shaped PSCs. Device structures and geometric parameters of the cone-shaped PSC are shown in Fig. 2. The layer $\mathrm{Al}(80 \mathrm{~nm}) / \mathrm{TiO}_{\mathrm{x}}(2 \mathrm{~nm})$ cathode is assumed to be a perfect mirror so that its absorption is ignored to simplify the calculation. The $n$ and $k$ of MEHPPV:PC ${ }_{71} \mathrm{BM}$ and PH1000 films with the thicknesses of $60 \mathrm{~nm}$ and $100 \mathrm{~nm}$ are put into the calculation. The incident light hits the cells at air-PH1000 interface from the basal 


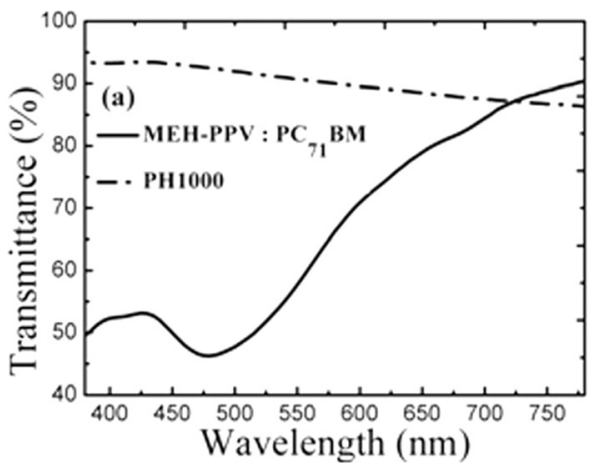

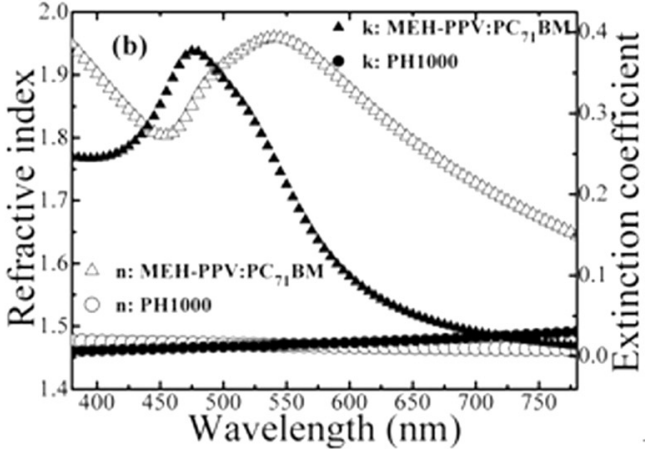

FIG. 1. (a) Transmittance spectra of the MEH-PPV: $\mathrm{PC}_{71} \mathrm{BM}$ and PH1000 films; (b) Refractive indices and extinction coefficients of MEH-PPV: $\mathrm{PC}_{71} \mathrm{BM}$ and PH1000 films. area of the cone with a direction paralleled to the axis. During the multiple reflections in the device, each ray presents many different angles of incidence to the active layer due to cone geometry. Therefore, the absorption of cone-shaped PSCs is changed with two variables, one is half cone angle $(\theta)$ and the other is wavelength of the light $(\lambda)$. During the simulations, the base areas of the cones $\left(S_{b}\right)$, served as the illuminated areas, are fixed by a radius $(r)$ of $5 \mathrm{~mm}$, thus lat-
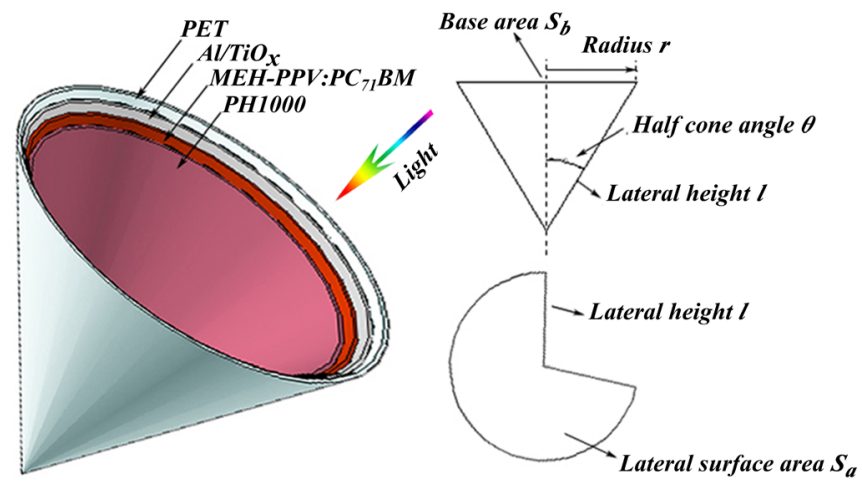

FIG. 2. Device structures and geometric parameters of the cone-shaped PSCs. eral surface areas of the cone $\left(S_{a}\right)$, served as the active areas of solar cells, are changed with $\theta$,

$$
S_{b}=\pi r^{2} ; \quad S_{a}=\pi r l=\pi r \times r \csc \theta .
$$

According to the absorption spectra of the active layer, the simulations are run in the range of $380-780 \mathrm{~nm}$. Due to the same projected illuminated areas $\left(S_{b}\right)$, there is an unchanged quantity of incident light for all cones in the simulation. As light cannot transmit through $\mathrm{Al}$, so that unabsorbed light would be reflected. Therefore, we can get the quantity of absorbed light $\left(\Phi_{a}\right)$ and compare with the incident light $\left(\Phi_{i}\right)$ to obtain absorption of the device $\left(A d_{\lambda, \theta}\right)$ with various $\theta$ and $\lambda$ (Fig. 3(a)) through the expression

$$
A d_{\lambda, \theta}=\phi_{a} / \phi_{i}
$$

For the lights in the range of $380-780 \mathrm{~nm}, A d_{\lambda, \theta}$ is increased with the decrease of $\theta$. At $\theta$ below $10^{\circ}, A d_{\lambda, \theta}$ is near $100 \%$ to form a black hole for incident light. $A d_{\lambda, \theta}$ presents light utilization of the cone-shaped PSCs. Now we define absorption of material $\left(A m_{\lambda, \theta}\right)$ to evaluate the utilization of material (all materials in PSCs) in the cone-shaped PSCs,
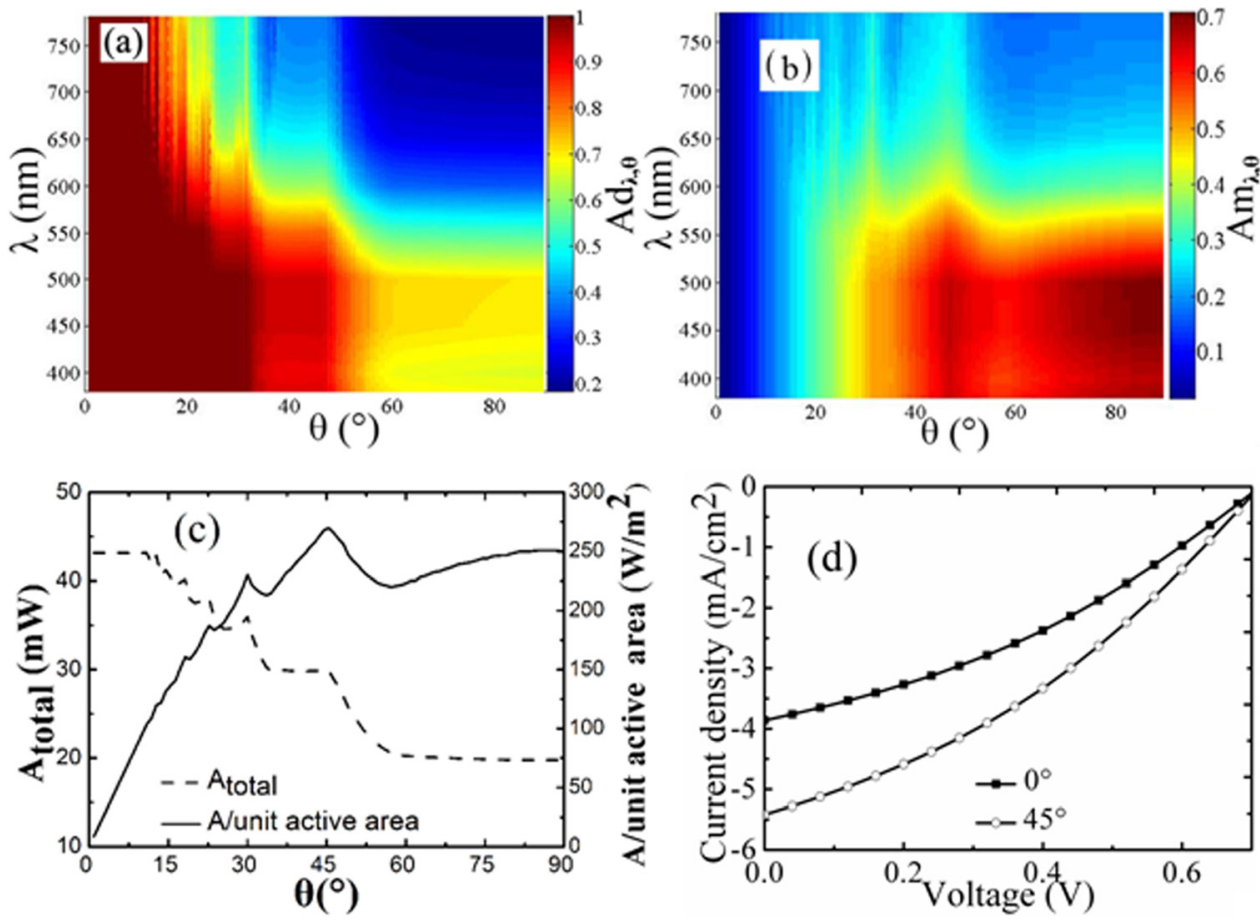

FIG. 3. (a) $A d_{\lambda, \theta}$ with various $\theta$ and $\lambda$. (b) $A m_{\lambda, \theta}$ with various $\theta$ and $\lambda$. (c) Total absorption $\left(\mathrm{A}_{\text {total }}\right)$ and absorption per unit active area (A/unit active area) of cone-shaped PSCs with various $\theta$. (d) The J-V of cone-shaped PSCs with $\theta$ of $0^{\circ}$ and $45^{\circ}$. 
TABLE I. Performances of PSCs under illumination of $100 \mathrm{~mW} / \mathrm{cm}^{2}$.

\begin{tabular}{lcccccc}
\hline \hline Half-angle $(\mathrm{deg})$ & $\begin{array}{c}\text { Illuminated } \\
\text { area }\left(\mathrm{cm}^{2}\right)\end{array}$ & $\mathrm{J}_{\mathrm{sc}}\left(\mathrm{mA} / \mathrm{cm}^{2}\right)$ & $\mathrm{V}_{\mathrm{oc}}(\mathrm{V})$ & $\mathrm{FF}$ & $\mathrm{PCE}(\%)$ & $\operatorname{Rs}\left(\Omega \mathrm{cm}^{2}\right)$ \\
\hline 0 & 0.05 & 6.3 & 0.76 & 0.44 & 2.12 & 31.0 \\
0 & 0.81 & 3.8 & 0.71 & 0.35 & 0.93 & 109.4 \\
45 & 0.57 & 5.4 & 0.71 & 0.35 & 1.33 & \\
\hline
\end{tabular}

$$
A m_{\lambda, \theta}=A d_{\lambda, \theta} \times\left(S_{b} / S_{a}\right) .
$$

The resulted $A m_{\lambda, \theta}$ with various $\theta$ and $\lambda$ is present in Fig. 3(b). $S_{b}$ is a constant, but $S_{a}$ is increased with the decrease of $\theta$, so $A m_{\lambda, \theta}$ decreased gradually with the decrease of $\theta$. The images in Figs. 3(a) and 3(b) present the relative light utilization and material utilization at various $\lambda$ for the cone-shaped PSCs, respectively. With standard sun light condition (AM 1.5) taken into the calculation, total absorption $\left(\mathrm{A}_{\text {total }}\right)$ and absorption per unit active area $(\mathrm{A} /$ unit active area) of the cone-shaped PSCs are shown in Fig. 3(c), which also show light utilization and material utilization, respectively. The light trapping of cone-shaped PSCs is less sensitive to the angle of incident light than that of V-shaped PSCs due to the multi-reflections in all directions. For $\theta$ below $30^{\circ}$, big $S_{a}$ effectively dilutes incident light on the active layer. When $\theta$ is between $30^{\circ}$ and $60^{\circ}$, the enhanced light utilization is achieved without much loss of material utilization. When $\theta$ is between $60^{\circ}$ and $90^{\circ}$, the cone-shaped PSCs present little differences from the planar ones. For the coneshaped PSCs studied in our work, a critical $\theta$ of $45^{\circ}$ presents a promising result, where highest material utilization meets a higher light utilization.

To confirm above calculation, the cone-shaped device with $\theta$ of $45^{\circ}$ and $r$ of $0.43 \mathrm{~cm}$ is fabricated and studied. The fabrication process of the cone-shaped PSCs is presented as follows: polyethylene terephthalate (PET) were cleaned with detergent and de-ionized water. $\mathrm{Al}(80 \mathrm{~nm}) / \mathrm{TiO}_{\mathrm{x}}(2 \mathrm{~nm})$ bilayer cathode was thermally evaporated onto the PET substrate through a sector shadow mask at pressure less than $10^{-3} \mathrm{~Pa}$ and exposed to air for $12 \mathrm{~h}$ to form $\mathrm{TiO}_{\mathrm{x}}$. Active layers were spin-coated at $600 \mathrm{rpm}$ from o-dichlorobenzene solution of MEH-PPV:PC ${ }_{71} \mathrm{BM}(1: 4 \mathrm{w} / \mathrm{w})$ at a total solids concentration of $20 \mathrm{mg} / \mathrm{ml}$ in a dry nitrogen glove box. The thickness of the active layers is about $60 \mathrm{~nm}$. PH1000 was spin-coated on the active layer at $1000 \mathrm{rpm}$ and annealed at $60^{\circ} \mathrm{C}$ for $30 \mathrm{~min}$, resulting in a thickness of around $100 \mathrm{~nm}$. Thickness was determined by a Dektak $6 \mathrm{M}$ surface profilometer. Finally, planar sector devices were rolled along their side edges and fixed with adhesive to form the coneshaped PSCs with active areas around $0.81 \mathrm{~cm}^{2}$. In addition, the planar sector devices before and after bending and the smaller planar devices with the active areas of $0.05 \mathrm{~cm}^{2}$ are also studied for comparison. Current-voltage characteristics were recorded using a Keithley 2400 Source meter under illumination of AM 1.5 with an intensity of $100 \mathrm{~mW} / \mathrm{cm}^{2}$ from a solar simulator (Model SS-50A, Photo Emission Tech., Inc.) under ambient conditions without encapsulation.
Device performance is summarized in Table I, and J-V characteristics of cone-shaped PSCs with half-angles of $0^{\circ}$ and $45^{\circ}$ are presented in Fig. 3(d). A high PCE of 2.12\% is achieved from the smaller planar device with a short-circuit current density $\left(J_{s c}\right)$ of $6.3 \mathrm{~mA} / \mathrm{cm}^{2}{ }^{22}$ Open-circuit voltage $\left(V_{o c}\right)$ and fill factor (FF) of the inverted PSCs are a little lower than the normal PSCs, which shows potential for the further optimization on device modification. For the planar sector device with an active area of $0.81 \mathrm{~cm}^{2}$, there is a loss of more than $50 \%$ in overall performance because high sheet resistance of PH1000 results in lower FF and $J_{s c}{ }^{23}$ The coneshaped device presents a higher $J_{s c}$ of $5.4 \mathrm{~mA} / \mathrm{cm}^{2}$, which is due to the enhanced absorption arising from the multiple reflections in the device. Compared with the planar device, the light utilization is enhanced by $43 \%$, and thus a PCE of $1.33 \%$ is achieved in the cone-shaped PSCs. When the active area $\left(S_{a}\right)$ of the cone-shaped PSC replaces the illuminated area $\left(S_{b}\right)$ in the calculation, a PCE of $0.94 \%$ presents a similar material utilization as the planar device. Both data of light utilization and material utilization are consistent with the simulations. Despite the high water absorptivity of PH1000, the PSCs show stable performance due to the stability of MEH-PPV in the study. More importantly, the device performances of PSCs are stable both in the bending and after the bending, which is demonstrated that PSCs are flexible enough for the unique non-planar application. In addition, PSCs with complementary absorption can potentially be employed into the cone structure to construct tandem devices.

In conclusion, we demonstrated cone-shaped PSCs with an inverted ITO-free structure: $\mathrm{Al} / \mathrm{TiO}_{\mathrm{x}} / \mathrm{MEH}-\mathrm{PPV}$ : $\mathrm{PC}_{71} \mathrm{BM} / \mathrm{PH} 1000$. Absorption of the cone-shaped PSCs is studied with Monte Carlo ray tracing, which presents different absorption profiles for the cones with various half cone angles. With small angle, there is effective light trapping in the cone-shaped PSCs due to the reabsorption in all directions. The cone-shaped PSCs at half cone angle of $45^{\circ}$ have the highest material utilization combined with a higher light utilization, which is confirmed in the device with a PCE of $1.33 \%$ and a $J_{s c}$ of $5.4 \mathrm{~mA} / \mathrm{cm}^{2}$. Apart from the effective light trapping, high stability of the cone-shaped PSCs in bending states will also cast lights on the non-planar application of PSCs.

This work was financially supported by the National Natural Science Foundation of China (No. 61007056) and Research Fund for the Doctoral Program of Higher Education of China (Grant No. 20100101120048). We also thank the financial support from Swedish Energy Agency, the Swedish Research Council (VR), and VINNOVA. 
${ }^{1}$ H. Y. Chen, J. H. Hou, S. Q. Zhang, Y. Y. Liang, G. W. Yang, Y. Yang, L. P. Yu, Y. Wu, and G. Li, Nat. Photonics 3, 649 (2009).

${ }^{2}$ S. H. Park, A. Roy, S. Beaupre, S. Cho, N. Coates, J. S. Moon, D. Moses, M. Leclerc, K. Lee, and A. J. Heeger, Nat. Photonics 3, 297 (2009).

${ }^{3}$ G. Yu, J. Gao, J. C. Hummelen, F. Wudl, and A. J. Heeger, Science 270, 1789 (1995).

${ }^{4}$ J. B. Emah, R. J. Curry, and S. R. P. Silva, Appl. Phys. Lett. 93, 103301 (2008). ${ }^{5}$ S. I. Na, S. S. Kim, J. Jo, S. H. Oh, J. Kim, and D. Y. Kim, Adv. Funct. Mater. 18, 3956 (2008).

${ }^{6}$ D. H. Wang, D. G. Choi, K. J. Lee, J. H. Jeong, S. H. Jeon, O. O. Park, and J. H. Park, Org. Electron. 11, 285 (2010).

${ }^{7}$ A. Lin and J. Phillips, Sol. Energy Mater. Sol. Cells 92, 1689 (2008).

${ }^{8}$ B. D. Boer, A. Hadipour, and P. W. M. Blom, Adv. Funct. Mater. 18, 169 (2008).

${ }^{9}$ J. Yang, R. Zhu, Z. R. Hong, Y. J. He, A. Kumar, Y. F. Li, and Y. Yang, Adv. Mater. 23, 3465 (2011).

${ }^{10}$ L. T. Dou, J. B. You, J. Yang, C. C. Chen, Y. J. He, S. Murase, T. Moriarty, K. Emery, G. Li, and Y. Yang, "Tandem polymer solar cells featuring a spectrally matched low-bandgap polymer," Nat. Photonics (in press).

${ }^{11}$ M. S. Kim, J. S. Kim, J. C. Cho, M. Shtein, L. J. Guo, and J. Kim, Appl. Phys. Lett. 90, 123113 (2007).

${ }^{12}$ K. Tvingstedt, V. Andersson, F. L. Zhang, and O. Inganäs, Appl. Phys. Lett. 91, 123514 (2007).
${ }^{13}$ V. Andersson, K. Tvingstedt, and O. Inganas, J. Appl. Phys. 103, 094520 (2008).

${ }^{14}$ Y. H. Zhou, F. L. Zhang, K. Tvingstedt, W. J. Tian, and O. Inganäs, Appl. Phys. Lett. 93, 033302 (2008).

${ }^{15}$ S. B. Rim, S. B. Zhao, S. R. Scully, M. D. McGehee, and P. Peumans, Appl. Phys. Lett. 91, 243501 (2007).

${ }^{16}$ Y. M. Sun, C. J. Takacs, S. R. Cowan, J. H. Seo, X. Gong, A. Roy, and A. J. Heeger, Adv. Mater. 23, 2226 (2011).

${ }^{17}$ S. D. Yambem, K. S. Liao, and S. A. Curran, Sol. Energy Mater. Sol. Cells 95, 3060 (2011).

${ }^{18}$ M. Manceau, D. Angmo, M. Jørgensen, and F. C. Krebs, Org. Electron. 12, 566 (2011).

${ }^{19}$ T. Zheng, L. M. Andersson, Z. George, K. Vandewal, K. Tvingstedt, P. Heriksson, R. Kroon, M. R. Andersson, and O. Inganas, Adv. Mater. 24, 554 (2012).

${ }^{20}$ H. Y. Zhen, G. L. Li, K. Y. Zhou, and X. Liu, Opt. Express 18, 15784 (2010).

${ }^{21}$ A. R. Forouhi and I. Bloomer, Phys. Rev. B 34, 7018 (1986).

${ }^{22}$ E. C. Chang, C. I. Chao, and R. H. Lee, J. Appl. Polym. Sci. 101, 1919 (2006).

${ }^{23}$ A. K. Pandey, J. M. Nunzi, B. Ratier, and A. Moliton, Phys. Lett. A 372, 1333 (2008). 